\title{
Effects of Intra-abdominal Pressure with Visual Feedback on Muscle Activation of Upper Trapezius and Sternomastoid during Forced Inspiration in Individuals with Costal Respiration
}

\author{
Kwang-Su Kim ${ }^{1}$, Hwa-Kyung Shin ${ }^{2}$ \\ 'Department of Physical Therapy, Graduate School, Daegu Catholic University, Daegu; ${ }^{2}$ Department of Physical Therapy, College of Bio and Medical \\ Science, The Graduate School, Daegu Catholic University, Daegu, Korea
}

Purpose: This study analyzed the immediate effects of intra-abdominal pressure with visual feedback on the muscle activation of the upper trapezius and sternomastoid during natural inspiration and forced inspiration in individuals with costal respiration.

Methods: The eighteen individuals with upper costal breathing pattern participated in this study. Surface electromyography was used to analyze the muscle activity of the upper trapezius and sternomastoid during natural inspiration and forced inspiration before and after intra-abdominal pressure.

Results: A significant difference in muscle activation was observed with the muscle type, inspiration type, and test session ( $p<0.05$ ). The muscle activities of the sternomastoid and upper trapezius decreased significantly during forced inspiration after intra-abdominal pressure training $(p<0.05)$. On the other hand, there was no significant difference during natural inspiration in both muscles $(p>0.05)$. A comparison of the difference between the pre-test and post-test during forced inspiration revealed the upper trapezius to be significantly larger than the sternomastoid $(p<0.05)$. No significant difference was noted during natural inspiration $(p>0.05)$.

Conclusion: The intra-abdominal pressure has positive effects on correcting the breathing patterns in individuals with costal respiration.

Keywords: Electromyography, Inspiration, Upper trapezius muscle.

\section{서 론}

배가로막(diaphragm)은 호흡의 주된 근육으로 가슴안(thoracic cavity)과 배안(abdominal cavity)을 나누는 돔모양의 근육힘줄 구조물이 다. 호흡은 들숨(inspiration)과 날숨(expiration)으로 나뉘는데, 들숨 시 배가로막이 수축하면 가슴 안이 아래로 넓어지며 폐는 팽창한다. 배가로막은 들숨 호흡의 $75 \%$ 를 담당한다. ${ }^{2}$ 그러나 배가로막이나 목 의 기능적 이상이 있을 경우에는 호흡보조근을 이용한 보상적 흥식 호흡을 하게 된다. 이전 연구에서 호흡에 문제가 있는 환자들을 대상 으로 배가로막을 이용한 호흡법이 목과 어깨의 근활성에 영향을 미 칠 수 있다고 보고하였다.-6 자세 안정화에 있어서 좋지 못한 호흡 습 관은 불안, 고혈압, 두통 등과 관련되어 있으며, ${ }^{7}$ 잘못된 호흡으로 인 한 목주위 근육의 긴장은 목 구조의 변형과 더불어 스트레스로 인해 두통이 발생한다고 한다. 그리고 배가로막 호흡은 더 나은 산소 공
급, 교감신경계의 하향 조절 및 부교감신경계의 상향 조절로 인해 안 정화근육과 큰 근육사이의 협응을 향상시키는 것은 물론 호흡보조 근의 과도한 활성을 감소시키는 경향이 있다고 하였다. ${ }^{9}$

배가로막 호흡법에 대한 선행연구에서 $\mathrm{Kim}$ 등은 배가로막 호흡 을 허리통증 환자에게 적용하였는데, 이 때 허리주위 근육의 근활성 도 증가하였다고 보고하였고, Lee와 $\mathrm{Kim}^{10}$ 은 만성요통환자를 대상으 로 한 배가로막 호흡은 통증 조절과 체간안정화에 유의한 효과가 있 다고 하였다. 그리고 근골격계 질환뿐만 아니라 다양한 분야에서 연 구가 있었는데 배가로막 호흡은 스트레스 지수 혹은 불안감을 감소 시켜준다고 하였다. ${ }^{11,12}$ 그러나 배가로막을 이용한 호흡의 중요성이 강조되고 있음에도 불구하고 배가로막을 이용한 호흡법에 대해 구체 적이고 정확한 방법에 대한 연구가 부족한 실정이다.

최근에 소개된 동적 신경근 안정화 개념의 기초가 되는 배가로막 을 이용한 복강내압(intra-abdominal pressure) 호흡 훈련은 들숨 시 흥
Received Mar 5, 2020 Revised Apr 21, 2020

Accepted Apr 23, 2020

Corresponding author Hwa-Kyung Shin

E-mail hkshin1@cu.ac.kr
Copylight (C)2020 The Korean Society of Physical Therapy

This is an Open Access article distribute under the terms of the Creative Commons Attribution Non-commercial License (https:// creativecommons.org/license/by-nc/4.0.) which permits unrestricted non-commercial use, distribution, and reproduction in any medium, provided the original work is properly cited. 
곽이 팽창되지 않고 하복부을 팽팽하게 팽창시켜 벌어지도록 교육시 키며, 모든 앞-가쪽의 배근육의 활성화에 초점을 맞추고 있다. ${ }^{13-15}$ 특 히, 복강내압 호흡 훈련은 배가로막, 복벽의 근육, 골반저근의 동시수 축이 일어나며, 복강내 압력을 높일 수 있는 장점이 있다. ${ }^{14-16}$ 그러나 복강내압호흡 훈련을 이용한 호흡보조근의 근활성도 변화를 구체적 으로 비교한 연구가 부족하다.

따라서 본 연구에서는 흥식호흡패턴을 가진 성인에게 배가로막을 이용한 호흡 훈련을 할 때 초음파를 이용한 시각적 되먹임을 통해 들 숨 시 들숨 보조근인 목빗근과 위등세모근의 근활성에 미치는 영향 을 확인하고자 하였다.

\section{연구 방법}

\section{1. 연구대상자}

대상자 선정 조건은 20-30대 성인남성 중 상부 흥식호흡 패턴을 지닌 성인 18 명을 대상으로 실시하였다. 대상자 선정 조건은 배가로막 검 사(diaphragm test)와 상지올림검사(arm lifting test)의 두 가지 검사법 에서 모두 양성으로 나타난 상부 흉식 호흡 패턴 대상자를 기준으로 선정하였다. ${ }^{14}$ 심폐관련 질환이 있는 사람, 신경학적 증상이 있는 사 람, 목뼈의 외상을 있었거나 수술을 받은 사람, 지시를 이해하고 수행 하지 못하는 사람은 제외하였다. 연구의 목적과 방법을 충분히 설명 한 후, 연구 참여에 동의한 대상자를 선정하였다. 본 연구는 대구가톨 릭대학교 기관생명윤리위원회(International Review Board, IRB)의 심 의를 거쳐 연구윤리 승인을 받아 진행하였다(IRB No. CUIRB-2019-0005).

\section{2. 실험방법}

\section{1) 초음파 영상 피드백에 의한 복강내압호흡 훈련}

바로 누운 자세에서 무릎을 굽힌 상태에서 앞위엉덩뼈가시 바로 안 쪽과 외측복벽을 엄지손가락과 집게손가락으로 촉지하여 들숨과 날 숨 시에 손가락을 가볍게 밀어내는 느낌으로 호흡을 하도록 지시한 다. 이 방법은 대상자가 배꼽을 당겨 배가로막 호흡을 하면서 다른 심 부안정화 근육의 활성을 유지할 수 있다는 사실을 인지하는 것이 중 요하다. ${ }^{14,17}$

실시간 초음파 영상에 의한 시각적 바이오피드백을 활용하여 10 분간 호흡운동을 실시하도록 하였다. 초음파 M-모드를 사용하여 배 가로막의 움직임 영상을 얻기 위하여 전도자를 빗장뼈 중간 부분에 서의 수직선에 위치한 우측 하부 갈비뼈 사이 공간에 가로로 위치시 켰다(Figure 1A). ${ }^{18,19}$ 초음파 영상에서 들숨 시 배가로막의 위쪽굽힘이 잘 나타난다는 것은 배가로막을 이용한 호흡이 잘 일어나는 것을 의 미하고, 위쪽굽힘의 움직임이 작다는 것은 배가로막보다 호흡 보조 근의 사용이 많은 호흡을 수행한다는 것을 의미한다. 따라서 배가로 막을 이용한 복강내압 호흡 시 배가로막의 위쪽굽힘 상태를 유지하 도록 연구자의 지시를 통해 호흡을 유지하도록 하였다(Figure 1B).

\section{2) 안정 들숨와 강제 들숨 동안 근전도 측정}

강제성 들숨에서 초음파 바이오 피드백을 이용한 복강 내압 훈련을 실시하고, 훈련 전과 후에 목빗근과 위등세모근의 즉각적인 근활성 도 변화를 비교하였다. 강제 들숨은 파워브리드(Power-breathe, Iron$\operatorname{man} \mathrm{K} 5, \mathrm{HaB}$ Ltd., UK)를 이용하여 최대로 숨을 들어마시게 하였다. 파워브리드는 저항강도 1-10단계 중 5단계를 설정하였고, 5 초간 유지
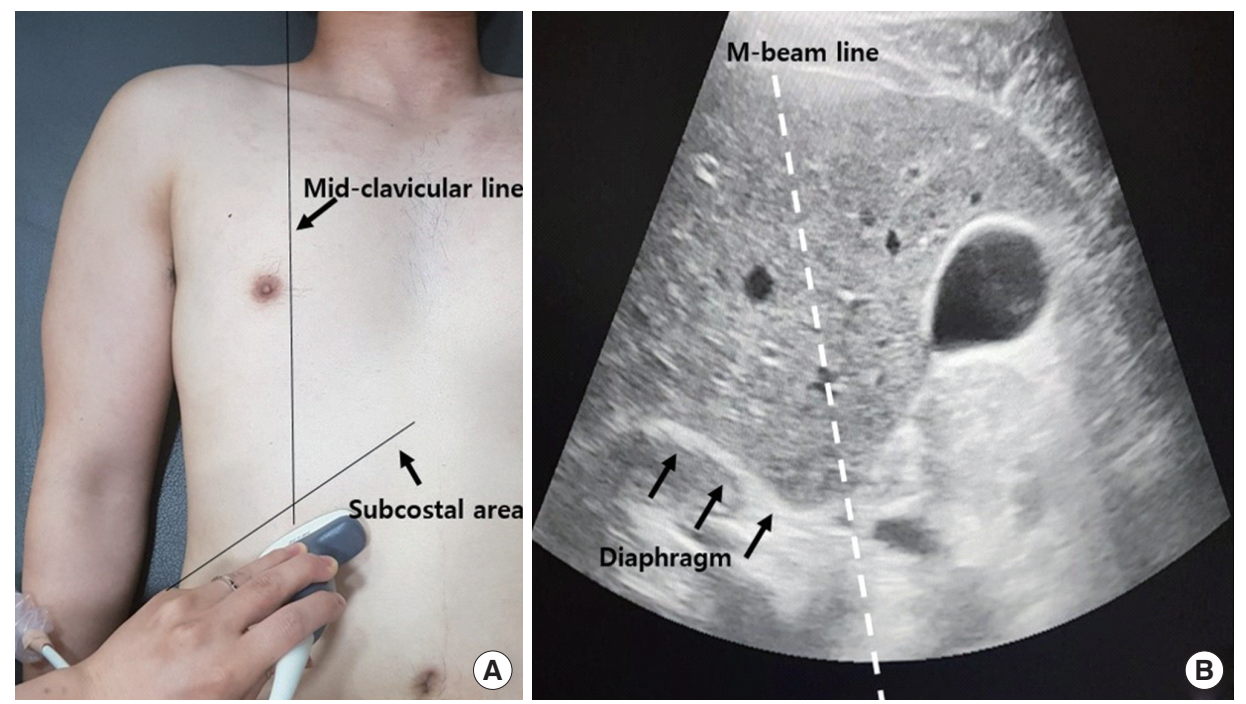

Figure 1. Ultrasound image during the inspiration. (A) Placement of ultrasound transducer to measure the diaphragmatic movement, (B) Example of M-mode ultrasound image to measure diaphragmatic movement from inspiration. 


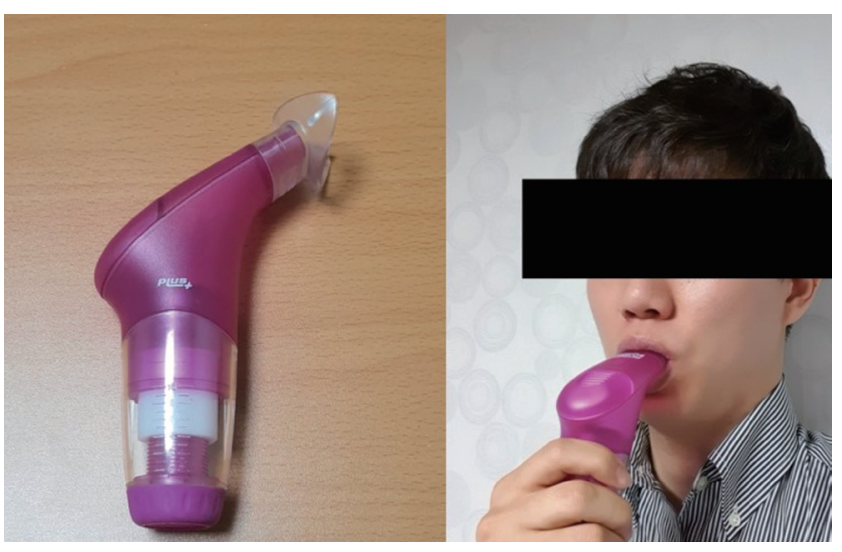

Figure 2. Power Breathe for forced inspiration.

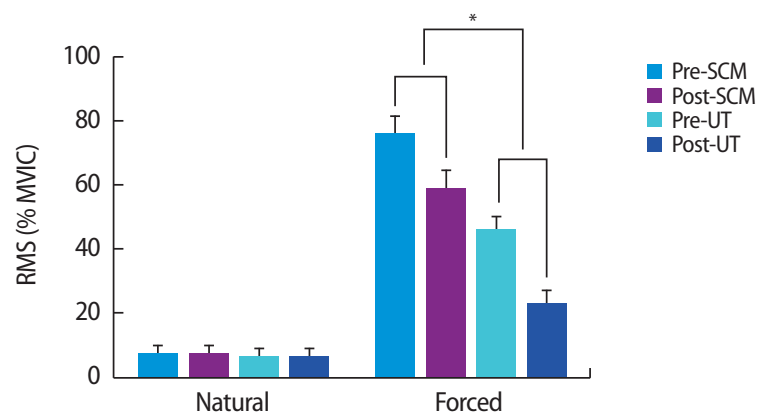

Figure 3. Comparison of muscle activation of the upper trapezius and sternomastoid during natural and forced inspiration in pre-test and post-test of intra-abdominal pressure. SCM: Sternomastoid, UT: Upper trapezius. ${ }^{*} p<0.05$.

Table 1. Comparison of EMG activation before and After training during inspiration

(unit: \%MVIC)

\begin{tabular}{|c|c|c|c|c|c|c|}
\hline Inspiration & Inspiration & Pre-test & Post-test & Differences & $\mathrm{t}$ & $p$ \\
\hline \multirow[t]{2}{*}{ Natural } & SCM & $6.61 \pm 3.54$ & $6.51 \pm 3.32$ & $0.01 \pm 3.81$ & 0.01 & 0.99 \\
\hline & UT & $5.75 \pm 2.99$ & $5.55 \pm 2.94$ & $0.09 \pm 1.15$ & & \\
\hline \multirow[t]{2}{*}{ Forced } & SCM & $75.25 \pm 6.17$ & $58.28 \pm 6.11$ & $16.96 \pm 7.42$ & 2.52 & $0.02^{*}$ \\
\hline & UT & $45.38 \pm 4.75$ & $22.52 \pm 4.51$ & $22.86 \pm 6.60$ & & \\
\hline
\end{tabular}

SCM: sternoomastoid, UT: upper trapezius. ${ }^{*} p<0.05$.

가능한 최대 강제 들숨을 하도록 중재 전 대상자에게 적절한 훈련방 법을 설명하고 장비 사용에 익숙할 때까지 연습하였다(Figure 2).

근활성도를 측정하기 위하여 Trigno wireless system (Delsys Inc., Boston, MA)을 사용하여 근전도 자료를 수집하고 Delsys EMGworks Analysis를 이용하여 분석하였다. 표본 수집률 $1,000 \mathrm{~Hz}$, 주파수 대역 필터 20-450 Hz에서 각 근육별 근전도 신호를 수집하고, 실효값(Root Mean Square, RMS) 처리하여 최대등척성수축력에 대한 백분율(\% $\mathrm{MVIC}$ )로 나타내었다. 5 초 측정하여 앞, 뒤 1 초를 제외한 3 초의 평균 값을 사용하였다.

대상자들에게 실험에 대한 절차를 설명한 후, 목빗근과 위등세모 근의 근활성도를 알아보기 위해 전극을 부착하였다. 피부저항을 낮 추기 위해 전극 부착 전 피부를 알코올솜으로 닦고, 필요에 따라 각질 제거를 위해 사포를 사용하였다. 전극의 부착부위는 목빗근은 꼭지 돌기와 빗장뼈의 중간지점, 그리고 위등세모근은 7번 목뼈의 가시돌 기와 어깨뼈 봉우리의 중간으로 정하였다. ${ }^{22,23} 3$ 회 측정하였으며, 측 정 사이에 5 분의 휴식시간을 두었다.

\section{3) 통계 분석}

실험을 통하여 수집된 자료는 IBM SPSS 22.0 (SPSS Inc., Chicago, IL, USA)을 사용하여 통계 분석하였다. 근육, 들숨 형태, 측정 시기에 따 른 반복측정 분산분석(Repeated Measures of ANOVA)을 실시하였으
며, 사후검정을 위하여, 본페로니 다중비교(Bonferroni’s multiple comparison test)를 실시하였다. 훈련 전과 후의 근활성의 차이에 대한 근 육 간 비교를 위하여 독립표본 t-검정(independent t-test)을 사용하였 다. 통계학적 유의 수준은 0.05 로 하였다.

\section{결 과}

본 연구에 참여한 연구대상자의 평균 나이는 평균 29.7세, 평균 체중 $74.7 \mathrm{~kg}$, 평균 신장 $176.8 \mathrm{~cm}, \mathrm{BMI}$ 지수는 23.9 이었다.

근육 종류에서 목빗근의 근활성도는 위등세모근에 비해 유의하게 높았으며 $(\mathrm{F}=251.1, \mathrm{p}<0.05)$. 호흡 형태에서 복강내압호흡 시의 근활성 도는 안정호흡에 비해 유의하게 높았다 $(\mathrm{F}=231.4 \mathrm{p}<0.05)$. 측정 시기 에서 훈련 후의 근활성도는 훈련 전에 비해 유의하게 낮았다 $(\mathrm{F}=$ 233.5, p < 0.05). 근육 종류, 호흡 형태, 측정 시기에 따른 상호작용은 없 었다 $(\mathrm{p}>0.05)$.

복강 내압 호흡훈련의 중재 후 강제 들숨 동안 목빗근의 근활성도 는 유의하게 감소하였고 $(\mathrm{t}=9.70, \mathrm{p}<0.05)$, 위등세모근의 근활성도도 유의하게 감소하였다 $(\mathrm{t}=14.70, \mathrm{p}<0.05)$. 또한 훈련 전과 후의 근육 간 근활성도의 차이 비교에서, 위등세모근이 목빗근보다 유의하게 크게 나타났다 $(\mathrm{t}=2.52, \mathrm{p}<0.05)$ (Figure 3). 반면, 복강 내압 호흡 훈련의 중재 후 안정 들숨 동안 목빗근 $(\mathrm{t}=0.11, \mathrm{p}>0.05)$ 과 등세모근 $(\mathrm{t}=0.33, \mathrm{p}>$ 
0.05)은 유의한 차이가 없었다(Table 1, Figure 3).

\section{고 찰}

본 연구는 흥식호흡패턴을 가진 건강한 성인에게 배가로막을 이용 한 훈련이 강제 들숨 시 목빗근과 위등세모근의 근활성도에 미치는 영향을 확인하였다. 그 결과 배가로막을 이용한 호흡 훈련 후에, 목빗 근과 위등세모근의 근활성도는 유의하게 감소하였다.

목빗근과 위등세모근은 안정 시 들숨 동안에는 거의 수축하지 않 지만, 숨을 크게 들이쉬거나 기침과 같이 호흡량이 증가하면 활성화 된다. 그러나 비정상적인 호흡패턴을 가진 사람은 정상적인 호흡을 가진 사람에 비해 목빗근과 위등세모근의 근활성도가 증가하게 된 다. ${ }^{22,24}$ 본 연구에서 훈련 전과 후의 근활성도는 강제성 들숨에서만 유의하게 감소하였다. 이는 배가로막을 이용한 훈련으로 인한 즉각적 인 효과라고 사료된다. 또한 본 연구에서 초음파 시각피드백을 이용 한 복강내압 훈련의 효과는 목빗근보다 등세모근의 근활성감소에 효 과적인 것으로 나타났다. 이는 목빗근의 과활성으로 인해 목 통증을 호소하는 환자를 위한 효과적인 치료 방법이 될 것으로 사료된다.

정상인을 대상으로 한 호흡보조근인 목빗근 억제에 대한 연구에 서 정상인 30 명을 대상으로 흥식호흡패턴이 있는 대상자가 목빗근의 근활성도가 유의하게 높다고 하였고, 목빗근의 근활성도를 낮추기 위해 배가로막호흡을 해야한다고 보고 하였다. ${ }^{23}$ 근전도 피드백을 이 용하여 위등세모근의 힘을 빼고 자세를 유지하여 목어깨의 긴장 감 소에 관한 연구에서 유의미한 효과가 있다고 보고하였다.25

본 연구를 선행연구와 비교해 볼 때, 기존 연구들에서는 배가로막 의 움직임을 객관화할 수 있는 도구로 측정 또는 평가하기 보다는 구 두 지시와 손을 이용한 촉진법처럼 주관적인 평가를 하였다.1,14,23,26 또 한 근전도 피드백을 통해 호흡보조근인 위등세모근의 억제를 유도하 였는데 이는 호흡을 통한 억제인지 어깨뼈내림근육(scapular depressor)의 활성을 통한 억제인지 평가되지 못했다. ${ }^{25}$ 하지만 본 연구에서 는 흥식 호흡 패턴을 가진 젊은 남성에게 초음파 시각적 되먹임을 이 용한 호흡 훈련을 실시하였다. 초음파 $\mathrm{M}$-모드를 사용하였을 때 배가 로막의 움직임을 평가하고 기능을 예측할 수 있는 장점이 있다. ${ }^{27}$ 따 라서 호흡 운동을 실시하는 동안 배가로막의 움직임 평가와 시각적 되먹임 도구로써 유용한 도구이기 때문에 초음파 M-모드를 배가로 막 훈련과 함께 활용하는 것은 상당히 효과적이라 할수 있다.

따라서 목, 어깨 부위의 통증이 있거나 두통이 있는 환자들 중 호 흡보조근을 과도하게 사용한다면 호흡패턴의 교정을 위해 초음파 시각적 되먹임을 보조도구로 활용하여 배가로막을 이용한 호흡 훈련 이 효과적일 수 있다. 하지만 본 연구의 결과를 해석하기에 고려해야 할 몇 가지 제한점이 있다. 첫째, 대상자들이 모두 20-30대 남성이었기
때문에 다른 성별과 다른 연령대의 대상자에게 일반화하기 어려움 이 있다. 둘째, 들숨 시의 근활성도를 비교하였고, 날숨 시의 근활성도 를 수집하지 않아 강제 들숨근의 이완 정도를 확인할 수 없었다. 셋 째, 배가로막을 이용한 훈련이 단기간의 효과를 검증하였으나, 장기 적 관찰 및 추적조사를 하지 못하였다. 따라서 향후 연구에서는 호흡 에 문제가 있는 대상자를 세분화하여, 호흡의 단계를 나누어 장기간 의 효과를 비교하기 위한 연구가 필요할 것이다.

\section{참고문헌}

1. Kim K, Park R, Bae S. Effect of diaphragmatic breathing exercise on activation of trunk muscle of patients with low back pain. J Kor Phys Ther. 2005;17(3):311-27.

2. Montes AM, Baptista J, Crasto C et al. Abdominal muscle activity during breathing with and without inspiratory and expiratory loads in healthy subjects. J Electromyogr Kines. 2016;30:143-50.

3. Hodges PW, Gandevia SC. Changes in intra-abdominal pressure during postural and respiratory activation of the human diaphragm. J Appl Physiol. 2000;89(3):967-76.

4. Kisner C, Colby LA, Borstad J. Therapeutic Exercise: Foundations and Techniques. Fa Davis. 2017.

5. Frank C, Page P, Lardner R. Assessment and Treatment of Muscle Imbalance: The Janda Approach. J Hum Kinet. 2009.

6. Celhay I, Cordova R, Miralles R et al. Effect of upper costal and costodiaphragmatic breathing types on electromyographic activity of respiratory muscles. CRANIO . 2015;33(2):100-6.

7. Hodges PW, Heijnen I, Gandevia SC. Postural activity of the diaphragm is reduced in humans when respiratory demand increases. J Physiol (Lond). 2001;537(3):999-1008.

8. Andersen $\mathrm{CH}$, Jensen $\mathrm{RH}$, Dalager $\mathrm{T}$ et al. Effect of resistance training on headache symptoms in adults: Secondary analysis of a RCT. Musculoskelet Sci Pract. 2017;32:38-43.

9. Rattray FS, Ludwig L, Beglin G. Clinical Massage Therapy: Understanding, Assessing and Treating Over 70 Conditions. Talus Incorporated. 2000.

10. Lee HJ, Kim SY. Comparison of the Effects of Abdominal Draw-In and Expansion Maneuvers on Trunk Stabilization in Patients with Low Back Pain and Lumbar Spine Instability. Phys Ther Korea. 2015;22(1):37-48.

11. Chen Y, Huang X, Chien C et al. The effectiveness of diaphragmatic breathing relaxation training for reducing anxiety. Perspect Psychiatr C. 2017;53(4):329-36.

12. Rygiel KK. Deep diaphragmatic breathing: A "Portable intervention" for stress reduction among university students. In: Effects of Stress on Human Health. IntechOpen. 2019.

13. Jull GA, Richardson CA. Motor control problems in patients with spinal pain: A new direction for therapeutic exercise. J Manipulative Physiol Ther. 2000;23(2):115-7.

14. Frank C, Kobesova A, Kolar P. Dynamic neuromuscular stabilization \& sports rehabilitation. Int J Sports Phys Ther. 2013;8(1):62-73.

15. Mahdieh L, Zolaktaf V, Karimi MT. Effects of dynamic neuromuscular stabilization (DNS) training on functional movements. Hum Move- 
ment Sci. 2020;70:102568.

16. Kane K, Barden J. Frequency of anticipatory trunk muscle onsets in children with and without developmental coordination disorder. Phys Occup Ther Pediatr. 2014;34(1):75-89.

17. Osar E. Corrective Exercise Solutions to Common Shoulder and Hip Dysfunction. BookBaby. 2012.

18. Boussuges A, Gole Y, Blanc P. Diaphragmatic motion studied by mmode ultrasonography: Methods, reproducibility and normal values. Chest. 2009;135(2):391-400.

19. Yamaguti WP, Claudino RC, Neto AP et al. Diaphragmatic breathing training program improves abdominal motion during natural breathing in patients with chronic obstructive pulmonary disease: A randomized controlled trial. Arch Phys Med Rehabil. 2012;93(4):571-7.

20. Criswell E. Cram's Introduction to Surface Electromyography. Jones \& Bartlett Publishers. 2010.

21. Kim K, Lee J, Lee J et al. Effects of instability tools on muscles activities in lunge exercise in healthy adult males. J Kor Phys Ther. 2019;31(6):363-7.

22. Yoon T, Kim K, Cynn H. Slow expiration reduces sternocleidomastoid activity and increases transversus abdominis and internal oblique muscle activity during abdominal curl-up. J Electromyogr Kines. 2014;24(2): 228-32.

23. Cagnie B, Danneels L, Cools A et al. The influence of breathing type, expiration and cervical posture on the performance of the cranio-cervical flexion test in healthy subjects. Man Ther. 2008;13(3):232-8.

24. Hudson AL, Gandevia SC, Butler JE. The effect of lung volume on the co-ordinated recruitment of scalene and sternomastoid muscles in humans. J Physiol (Lond). 2007;584(1):261-70.

25. Ma C, Szeto GP, Yan T et al. Comparing biofeedback with active exercise and passive treatment for the management of work-related neck and shoulder pain: A randomized controlled trial. Arch Phys Med Rehabil. 2011;92(6):849-58.

26. Ostwal PP, Wani S. Breathing patterns in patients with low back pain. Int J Physiother Res. 2014;2(1):347-53.

27. Epelman M, Navarro OM, Daneman A et al. M-mode sonography of diaphragmatic motion: Description of technique and experience in 278 pediatric patients. Pediatr Radiol. 2005;35(7):661-7. 